\title{
Measuring the risk of climate variability to cereal production at five sites in Spain
}

\author{
Ana Iglesias ${ }^{1, *}$, Sonia Quiroga ${ }^{2}$ \\ ${ }^{1}$ Department of Agricultural Economics and Social Sciences, Universidad Politécnica de Madrid, Avenida de la Moncloa, \\ 28040 Madrid, Spain \\ ${ }^{2}$ Department of Applied Economics, Universidad de Alcalá, Plaza de la Victoria 2, Alcalá de Henares, 28602 Madrid, Spain
}

\begin{abstract}
This study provides a method with which to measure the risk of climate variability to agriculture among geographic regions, and analyses the potential risk to crop yields in Spain. Our methodology comprised 3 steps: (1) models were developed for each region to estimate the risk of climate variability, and functional forms were derived from $60 \mathrm{yr}$ of empirical data on wheat; (2) Monte Carlo models were used to analyse in more detail the probabilistic properties of the agricultural yields; (3) a risk factor index was applied to compare among 5 sites. An advantage of this methodological approach is that it links agricultural areas with representative meteorological stations and uses a Monte Carlo approach to define large samples of crop yields that more accurately reflect the statistical properties needed for risk analysis. The methods were robust enough to develop climate and management scenario analysis, which was applied to 5 case studies that exemplify other Mediterranean areas in which climate is a main source of agricultural risk and exerts pressure on limited water supplies, for which there are competing demands. The results show that risk characterization is complex, owing to the multiple attributes of risk beyond climate variability, and that our method of risk analysis facilitates comparisons among locations.
\end{abstract}

KEY WORDS: Drought $\cdot$ Risk analysis $\cdot$ Rainfed cereals $\cdot$ Wheat $\cdot$ Crop yield $\cdot$ Mediterranean

Resale or republication not permitted without written consent of the publisher

\section{INTRODUCTION}

Over the last few decades, an increasing body of observations has emphasized the importance of managing climate risk to the optimization of crop choice and farm income, especially in marginal areas (Jones et al. 2000, Adams et al. 2004, Kumar et al. 2004, Botterill \& Wilhite 2005). Climate risks to agriculture vary according to location, type of enterprise, and the effectiveness of risk management (Iglesias \& Moneo 2005). Crop production is sensitive not only to annual changes but also to the seasonal distribution of precipitation (Mjelde et al. 1998, Ogallo et al. 2000).

Even if farmers' behaviour is difficult to change (e.g. owing to imposed policies or to a limitation of available choices), an improved knowledge of crop-climate interactions is certain to enhance farm performance (Cane et al. 1994, Hammer et al. 1996, Hansen \& Indeje 2004). Most assessments of regional climate risk pro- vide only probabilistic information on climate (Hansen \& Indeje 2004). Risk analysis has evolved from the evaluation of probabilities of climate hazard alone to more integrated approaches that include probabilistic information on the system at risk, thus boosting the relevance of results to risk management (Botterill \& Wilhite 2005, Wilhite 2005). This latter approach is challenging owing to limitations in the availability and validation of non-climatic data.

A major challenge facing all agriculture-climate evaluations is the inclusion of both biophysical and socioeconomic aspects in the methodology. Numerous studies have used agricultural simulation models to capture these complex interactions. Approaches which link crop models with global climate and seasonal forecast models have been evaluated in Africa (Hansen \& Indeje 2004) and Australia (Hansen et al. 2004). Multiple regression models have been developed to represent process-based yield responses to 
these environmental and management variables: yield functions have been used to evaluate the sensitivity and adaptation to climate e.g. in Spain (Iglesias et al. 2000), California (Lobell et al. 2005) and globally (Parry et al. 2004), and could be used to estimate the risk associated with climate variability (as in Ferreyra et al. 2001), with potential applications in crop insurance (Luo et al. 1994, Hertzler 2005).

There are many definitions of risk. Broadly speaking, risk may be described as the capacity of a system to suffer losses when exposed to an external stressor (Wisner et al. 2004). The risk-hazards framework applied in the United Nations International Strategy for Disaster Reduction (UNISDR) has provided scientists in the natural hazards community with a tested methodology for evaluation of risk, that is 'the probability of harmful consequences, or expected losses resulting from interactions between natural or human induced hazards and vulnerable conditions' (UNISDR 2002 ${ }^{\mathbf{1}}$ ).

Regardless of the nuance of the analysis, risk is a relative measure - critical levels of risk must be defined by the analyst. Every system is at risk, albeit that risk levels differ in their causal structure, their evolution, and the severity of their likely consequences. In this study we focused on climate risk brought about by drought, because drought has severe consequences in Mediterranean systems, and the probability of its occurrence dominates decision making (as do many significant problems, especially those with non-linear payoff functions) (Patt 1999).

Risk analysis bridges the gap between impact assessment and policy formulation by directing policy attention to the consequences (i.e. crop yield) rather than to its agent (i.e. climate) (Rossi et al. 2003, Botterill \& Wilhite 2005, Garrote et al. 2007). This approach underlines the causes of differential risk among regions, such as small farm size, lack of credit for diversification, farming on marginal lands, limited knowledge, lack of local industry for off-farm supplementary income, or inadequate policies.

Risk analysis is used loosely in many different contexts, from medicine to analysis of poverty and from economic and social development to engineering (Bonaccorso et al. 2003; see footnote 1). To characterise risk in social systems, such as agriculture, it is important to focus on the consequences of a perturbation (e.g. decreased crop yield), rather than its agent (e.g. rainfall). In the context of agricultural management, the concept of risk is often derived from the climate sciences and the insurance literature. These approaches focus on the risk created

15ee also www.unisdr.org/eng/library/lib-terminology-eng \% 20home.htm from an external hazard and aim to identify potential damage; in contrast, the social sciences focus on the internal dimension of the potential damage (Wisner et al. 2004). In agriculture, the attributes of the internal dimension depend on the geographic area and the social conditions. Some studies have incorporated these concepts to analyze agricultural risk (Mjelde et al. 1997, Messina et al. 1999, Ferreyra et al. 2001). Nevertheless, there are no clear methodological approaches that include multi-stress relationships among different geographic regions.

This study provides a methodology for measuring agricultural risk to climate among geographic regions, integrating both empirical and probabilistic information, and analyses the effect of different risk scenarios on potential yields. The analysis focuses on wheat production: this cereal crop is a reference crop for agricultural policy, has a wide array of insurance products, and its yield level is an indicator of agricultural technology. The approach is based on the (1) development of empirical models for each region; (2) diagnostic characterization of risk based on Monte Carlo simulations; and (3) development of a risk factor index in order to compare climate response among different areas. By adopting this approach we can answer 3 critical questions that relate to explicit concerns of the agriculturalist: Where are the vulnerable farming systems located? Are potential region-specific measures necessary? Are worst-case scenarios an adequate indicator of risk? By enabling an understanding of these critical questions under the current climate regime, the analysis in this study provides insights into the range of risks of climate change.

\section{DATA AND METHODS}

\subsection{Case studies and data sources}

The methodology developed in this study was applied to selected case studies in Spain. Climatic and agricultural conditions are very diverse, owing to the varied topography, climate, production systems, technology, and social conditions (see Fig. 1 \& Table 1). Crop production in Spain varies by up to $20 \%$ percent from year to year, largely as a result of highly variable weather conditions. Only $40 \%$ of the land area of Spain is suitable for cultivation (Iglesias et al. 2000). The climate in Spain is Mediterranean, with hot, dry summers and cold, wet winters. In general, precipitation is concentrated between October and April (southern regions) or May (northern regions). Average seasonal temperature decreases with increasing altitude and latitude. The weather is characterised by large interannual variability. Sum- 
mer precipitation (June, July, and August) is well below $100 \mathrm{~mm}$ in all regions except the northwest, necessitating supplementary irrigation during part of the crop cycle in order to obtain adequate production levels. Coefficients of variation (CV) for precipitation vary from 21 to $55 \%$, implying a high risk of rainfed crop failures and the need for supplementary irrigation in order to meet full crop water requirements and achieve potential yield.

Five sites were selected to represent the major rainfed and irrigated agricultural regions of Spain (Fig. 1). Winter cereals, especially wheat, are grown in all areas; barley is grown in marginal areas. The case studies exemplify other Mediterranean regions where climate is a main source of agricultural risk and exerts pressure on limited water supplies (Iglesias et al. 2007a).

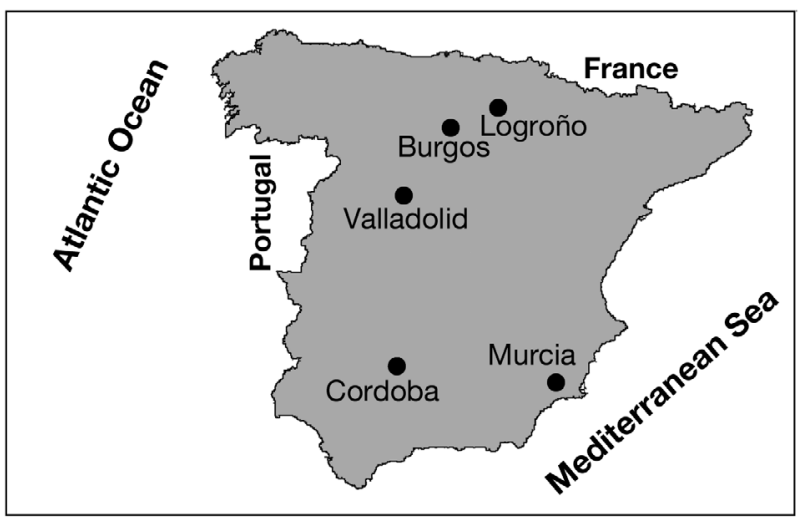

Fig. 1. Location of study sites in Spain
Monthly time series of average, maximum and minimum temperature, total precipitation, and number of days per month with temperature below $0^{\circ} \mathrm{C}$ for the period 1940 to 2000 were provided by the Spanish National Meteorological Institute (INM, see www.inm.es) for the stations listed in Table 1 and Fig. 1. Annual crop production data for the 1940 to 2000 period at the provincial level (a province is an administrative unit in Spain) for the selected sites were obtained from the Statistical Division of the Spanish Ministry of Agriculture (MAPA 2004).

\subsection{Risk analysis framework}

Fig. 2 summarizes the methodology. (1) Models were developed for each region in order to estimate the risk of climate variability: here we developed multiple linear regression models with climatic data as explanatory variables and validated the models for the case studies. (2) Monte Carlo models were used to analyse in more detail the probabilistic properties of the agricultural yields. (3) A risk factor index was applied in order to compare the risk of attaining low yields owing to climate among 5 sites. An advantage of this methodological approach is that it links agricultural areas with representative meteorological stations and uses a Monte Carlo approach to define large samples of crop yields that more accurately reflect the statistical properties needed for risk analysis. The methods are robust enough to allow further development of climate and management scenario analysis.

Table 1. Environmental and agricultural characteristics of sites included in this study

\begin{tabular}{|c|c|c|c|c|c|c|c|}
\hline Site & $\begin{array}{l}\text { Lat. } \\
\left({ }^{\circ} \mathrm{N}\right)\end{array}$ & $\begin{array}{l}\text { Long. } \\
\left({ }^{\circ} \mathrm{W}\right)\end{array}$ & $\begin{array}{l}\text { Altitude } \\
\quad(\mathrm{m})\end{array}$ & $\begin{array}{l}\mathrm{T}_{\mathrm{av}} \\
\left({ }^{\circ} \mathrm{C}\right)\end{array}$ & $\begin{array}{l}\text { Prec. } \\
(\mathrm{mm})\end{array}$ & Environmental characteristics & Agricultural system \\
\hline \multicolumn{8}{|c|}{ Northern Plateau } \\
\hline Burgos & 42.37 & 3.63 & 894 & 10.2 & 630 & \multirow{2}{*}{$\begin{array}{l}\text { High altitude, late spring } \\
\text { frost, large seasonal differ- } \\
\text { ences in temperature }\end{array}$} & \multirow{2}{*}{$\begin{array}{l}\text { Traditional low-input cereal } \\
\text { production with limitations in } \\
\text { soils and terrain }\end{array}$} \\
\hline Valladolid & 41.65 & 4.77 & 734 & 12.1 & 373 & & \\
\hline \multicolumn{8}{|l|}{ La Rioja } \\
\hline Logroño & 42.45 & 2.33 & 353 & 13.4 & 383 & $\begin{array}{l}\text { Similar to Northern Plateau } \\
\text { sites, but with a longer } \\
\text { frost-free period }\end{array}$ & $\begin{array}{l}\text { Grapevine area with high } \\
\text { technology; soils and climate } \\
\text { adequate for cereal production }\end{array}$ \\
\hline \multicolumn{8}{|c|}{ Guadalquivir Valley } \\
\hline Córdoba & 37.85 & 4.83 & 92 & 17.9 & 674 & $\begin{array}{l}\text { Mediterranean climate, long } \\
\text { frost-free season and adequate } \\
\text { winter precipitation for dryland } \\
\text { production, but with severe } \\
\text { recurrent drought periods }\end{array}$ & $\begin{array}{l}\text { Highly productive cereals and } \\
\text { olive trees }\end{array}$ \\
\hline \multicolumn{8}{|c|}{ Southeast coast } \\
\hline Murcia & 38.00 & 1.10 & 0 & 17.6 & 305 & $\begin{array}{l}\text { Coastal area with warm } \\
\text { winters and extremely limited } \\
\text { spring precipitation }\end{array}$ & $\begin{array}{l}\text { Cereal production only in } \\
\text { marginal areas; intensive irrigated } \\
\text { horticulture and citrus fruits }\end{array}$ \\
\hline
\end{tabular}




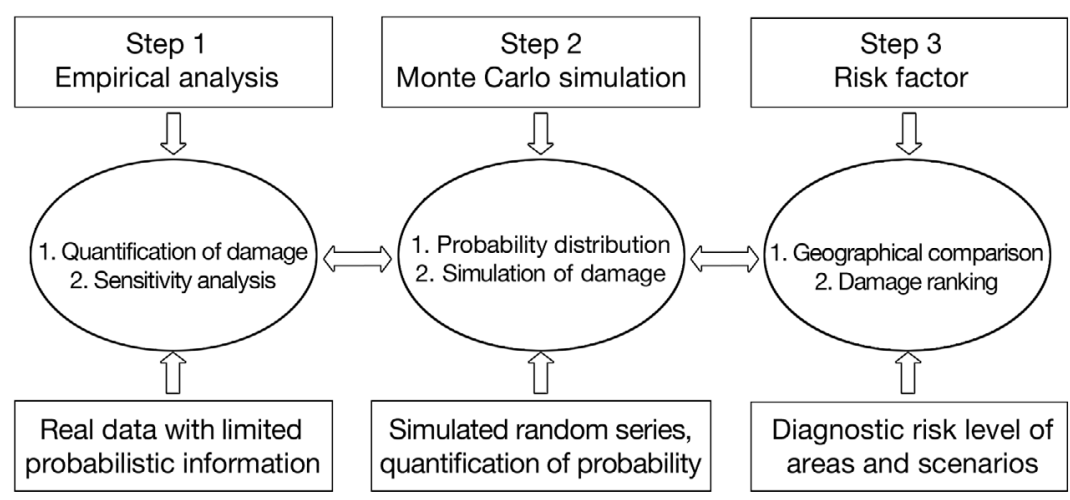

Fig. 2. Components of the risk analysis method used in this study

model to minimize the autocorrelation of the residuals and capture the dynamics of the data.

The sites selected exhibited differences in seasonal temperature as well as in the amount and distribution of precipitation (Fig. 1). To take into consideration possible accumulative effects, we calculated the 3 mo period of aggregation of all the climatic variables.

Variability in precipitation is very high and recurrent drought periods affect agricultural production at all sites. Drought characterisation is difficult owing to its spatial and temporal

\subsection{Empirical analysis}

Multiple linear regression models were estimated using climatic data as explanatory variables. Our goal was to understand the components of yield variability in a range of agro-climatic conditions. (1) Agricultural data were transformed to take into account the yield trend (see below for details). (2) Some climate variables were aggregated into seasonal time periods to increase the correlation with agricultural variables. (3) Multiple linear regression models were estimated.

Agricultural time series are non-stationary because they nearly always present a trend. When variables are non-stationary, normal regression analysis requires a transformation of the data. When there is not enough information about the causes of such a trend, the transformation needed to generate a stationary variable may be attained by simply removing deterministic trends (that is by directly subtracting the trend value from the observations or 'simple detrending'); by taking first-differences (that is the variable in year $t\left[Y_{t}\right]$ minus the variable in year $\left.t-1\left[Y_{t-1}\right]\right)$; or by introducing an autoregressive term as an independent or explanatory variable. In our case, we assumed that there is a causal relationship between yield increase and technological change; therefore, we used the technological and management variables to explain yield trend. A time series $X_{t}$ (in our case technological and management variables) is said to influence another series $Y_{t}$ (in our case crop yield) if the future values of $Y_{t}$ can be better predicted when the information contained in $X_{t}$ is included than when that information is excluded (Kang 1985).

We incorporated management indicators (farm equipment and amount of fertiliser used) as explanatory or independent variables in order to attempt to explain the positive trend in the yield data. However, at times the data exhibited some patterns that these management indicators were not able to explain. In these cases, autoregressive terms were included in the properties, and consequently a range of indicators are used (Bradford 2000, Keyantash \& Dracup 2002; see also www.drought.unl.edu/whatis/indices.htm). We opted for the commonly used Standardised Precipitation Index (SPI; McKee et al. 1993). The SPI calculates the difference in accumulated precipitation between a selected site and the average precipitation over the total area considered within the aggregation period. For its calculation, the precipitation record is normalized so that all precipitation values vary around 0 and areas with different climates can be compared relative to each other (McKee et al. 1993). We decided on an aggregated period of 12 mo and defined the threshold of drought as SPI values less than -1, following previous work in Spain (Moneo 2005, Garrote et al. 2007, Iglesias et al. 2007b).

Owing to the large number of climate variables considered (one for each $1 \mathrm{mo}$ and $3 \mathrm{mo}$ period) and to the high correlation between some variables, the climate effects were studied separately. This may result in the introduction of multicollinearity into the regression and consequently decrease the degrees of freedom. The $95 \%$ confidence intervals were estimated in order to avoid multicollinearity and improve particular model estimation, assuming normality of the residuals and considering significant relationships in the final specification. We then used Akaike's (1973) and Schwarz's (1978) criteria to assist in the selection of suitable models. The semi-logarithmic transformation of the independent variable is useful when interpreting the model's coefficients as semi-elasticities.

The model has the form

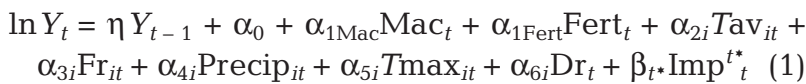

where the model output $\left(Y_{t}\right)$ is the crop yield at a site in Year $t$ and the inputs are of 2 types: management and climate variables (Table 2). We considered a range of climate variables, such as average temperature $\left(\operatorname{Tav}_{i t}\right)$, total precipitation $\left(\right.$ Precip $\left._{i t}\right)$, maximum temperature 
Table 2. Agricultural variables included in crop-yield functions, and sources of data used. MAPA: Ministry of Agriculture, Statistical Division; FAO: Food and Agriculture Organization, Statistical Division (available at http://apps.fao.org); INM: National Institute of Meteorology (available at www.inm.es); SPI: Standardised Precipitation Index

\begin{tabular}{|c|c|c|c|c|}
\hline $\begin{array}{l}\text { Type of } \\
\text { variable }\end{array}$ & Name & Definition & Unit & $\begin{array}{l}\text { Source of } \\
\text { data }\end{array}$ \\
\hline Output & $Y_{t}$ & Crop yield at a site in year $t$ & $\mathrm{tha}^{-1}$ & MAPA \\
\hline Management & $\begin{array}{l}\operatorname{Mac}_{t} \\
\text { Fert }_{t}\end{array}$ & $\begin{array}{l}\text { Engine power of farm equipment in year } t \\
\text { Total consumption of nitrogen fertilizer in year } t\end{array}$ & $\begin{array}{c}\mathrm{Cv} \\
\mathrm{t}\end{array}$ & $\begin{array}{l}\text { MAPA } \\
\text { FAO }\end{array}$ \\
\hline Climate & $\begin{array}{c}\operatorname{Tav}_{i t} \\
\operatorname{Tmax}_{i t} \\
\operatorname{Precip}_{i t} \\
\operatorname{Fr}_{i t}\end{array}$ & $\begin{array}{l}\text { Average temperature in the } i \text { th month } / 3 \text { mo period of year } t \\
\text { Maximum temperature in the } i \text { th month } / 3 \text { mo period of year } t \\
\text { Total precipitation in the } i \text { th month } / 3 \text { mo period in year } t \\
\text { No. of days with temperature below } 0^{\circ} \mathrm{C} \text { in the } i \text { th month } / 3 \text { mo } \\
\text { period in year } t\end{array}$ & $\begin{array}{c}{ }^{\circ} \mathrm{C} \\
{ }^{\circ} \mathrm{C} \\
\mathrm{mm} \\
\mathrm{d}\end{array}$ & $\begin{array}{l}\text { INM } \\
\text { INM } \\
\text { INM } \\
\text { INM }\end{array}$ \\
\hline & $\operatorname{Dr}_{t}$ & Dummy variable indicating drought years & $\begin{array}{c}1 \text { or } 0 \text { as a } \\
\text { function of SPI }\end{array}$ & $\begin{array}{l}\text { SPI elaborated } \\
\text { from INM data }\end{array}$ \\
\hline $\begin{array}{l}\text { Instrumental } \\
\text { variables }\end{array}$ & $\operatorname{Imp}_{t}$ & Impulse dummy variable & 1 or 0 & \\
\hline
\end{tabular}

$\left(\operatorname{Tmax}_{i t}\right)$, number of days per month with temperature below $0^{\circ} \mathrm{C}\left(\mathrm{Fr}_{i t}\right)$, and a dummy variable indicating drought years $\left(\mathrm{Dr}_{t}\right)$. Also, some impulse $\left(\operatorname{Imp}^{t^{*}}{ }_{t}\right)$ dummy variables were added to the model in order to isolate the effects of some anomalous years. A step dummy switches from 0 to 1 in the anomaly year, and an impulse dummy has a value of 1 only in that year (Table 3 in 'Results and Discussion' gives the years for which dummy variables were used). In addition, we considered a range of management variables - such as farm equipment power $\left(\mathrm{Mac}_{t}\right)$ and nitrogen fertilizer $\left(\right.$ Fert $\left._{t}\right)$ - that account for large increases in crop productivity. These management variables are commonly used in agricultural statistics at different spatial scales. For example, data on the engine power of farm equipment is collected as a proxy variable for technology and investment in a farm or in the farming sector of a district or country.

We estimated functions that only take into account the production side of the farm. The climatic and technological variables considered define the supply component but do not represent the demand component of the farming system - an essential element of agricultural risk, but one that is beyond the scope of this study.

\subsection{Monte Carlo simulations}

Monte Carlo simulations are widely used to derive large samples sizes from short time series of observed data (Robert \& Casella 1999). The Monte Carlo method is used in agriculture to characterize statistical properties of crop yield prices, as well as crop yield in response to rainfall or other inputs (Limaye et al. 2004, Gibbons \& Ramsden 2005, Lobell \& OrtizMonasterio 2006).
Here we applied Monte Carlo methods to derive probability distribution functions of yield risk levels. The approach consists of generating synthetic series of yield variables using the Monte Carlo method and Latin hypercube sampling (Just \& Weninger 1999, Atwood et al. 2003). Fig. 2 includes this step in the overall methodology.

Monte Carlo methods are an important component of uncertainty and probabilistic risk assessment, because they allow generation of random samples of statistical distributions (Robert \& Casella 2004). Monte Carlo methods simulate the behaviour of a system in a non-deterministic (stochastic) manner by using random numbers as opposed to deterministic algorithms. The Latin hypercube technique (McKay et al. 1979) is a variation of the simple Monte Carlo technique that employs a constrained sampling scheme used when the dependent variable $(y)$ is a function of several other variables $(x 1, x 2, \ldots, x k)$, as is the case for crop yield.

\subsection{Risk factor}

Risk as a function of climate is evaluated following the risk analysis of Ferreyra et al. (2001), who proposed an approach to quantify outcome risk for each station and climate scenario (ENSO and neutral years) based on a comparison of the probability of exceeding a given yield at each station with the corresponding probability at a reference station. We adapted Ferreyra et al.'s (2001) method to compare climate risk among 5 sites. We first selected a reference station and then computed the empirical cumulative probability distribution (EPCF) of the variable of interest (yield) for both the reference station $\left(\mathrm{EPCF}_{r}\right)$ and the station of interest $\left(\mathrm{EPCF}_{i}\right)$. The risk factor (RF) curve is computed as 


$$
\mathrm{RF}_{i}=\log _{10}\left(\mathrm{EPCF}_{i} / \mathrm{EPCF}_{r}\right)
$$

The selection of a reference station was based on the criteria of having a distribution of yields closer to a 'normal' distribution (see 'Results and Discussion'). The logarithm was constructed so that RF values were proportionally similar for EPCF ratios greater or lower than 1, and that the reference level (indicating no shift in probability with respect to the reference station) was 0 (Ferreyra et al. 2001). When comparing RF curves for the different sites, 4 'reference quantiles' were used for the reference station: the 10th, 30th, 60th and 90th percentiles. At each location, when RF is 0 , the probability of the crop being at risk is the same as that at the reference station, which was selected to represent a normal distribution of probability of crop yields. When RF is $>0$, the crop is at risk: the probability of surpassing any given outcome is smaller than that predicted at the reference station. In contrast, when $\mathrm{RF}$ is $<0$, the probability of surpassing any given outcome is greater than that predicted at the reference station.

\section{RESULTS AND DISCUSSION}

\subsection{Empirical analysis}

\subsubsection{Crop yield variability}

Despite a continued increase in crop yields owing to improved technology and management, yield variability has significantly increased over the last 3 decades. The standard deviation of crop yield in 1970 to 2000 is at least 3 times greater that in 1940 to 1970 at all sites. In order to explain yield variability, we estimated regression models that incorporated a range of variables. Meteorological variables explain a large component of the year-to-year crop yield variability, and drought events are a key variable in all areas of the country (Table 3).

We conducted several diagnostic tests on the estimated functions in order to evaluate their adequacy for simulating yield among geographic areas. Simulated crop yields were highly correlated with the observed yields: the adjusted $\mathrm{R}^{2}$ values range from 0.68 to 0.94 , and the parameters in the multiple regression functional forms are all significant at the 95\% level (Table 3). The Ljung-Box Q test, based on the autocorrelation plot, was calculated for all the regressions, and White's general test (White 1980) for each regression was used to test for the absence of conditional heteroscedasticity.

Because the model presents a semi-logarithmic transformation, the coefficients of the model can be interpreted as semi-elasticities; that is, the propor- tional change over the dependent variable when a unit variation is produced over the explanatory variable. For example, the most important factor for wheat yields in Murcia has been drought, because a dry year causes a yield reduction of approximately $21 \%$.

The derived models are coherent with the agroclimatic processes at each site. The production function for wheat in Murcia is interpreted below as an example (Fig. 3); we have the following estimated model (where $Y_{t}$ is the estimated crop yield)

$$
\begin{aligned}
\ln Y_{t} & =2.0751+0.0017 \mathrm{Mac}_{t}+0.0035 \text { Precip }_{\text {Mart }} \\
& +0.0034 \text { Precip }_{\text {Mayt }}-0.0857 \text { Tmax }_{\text {Jult }}-0.2138 \mathrm{Dr}_{t} \\
& -1.2966 \mathrm{Imp}_{1981_{t}-0.7908 \mathrm{Imp}_{\mathrm{m}} 1995_{t}}
\end{aligned}
$$

The variables that have a positive influence on wheat yields are farm technology and precipitation during March and May, while maximum temperature in July and drought episodes are important negative variables. The model recognises the drought event of 1981 and 1995 as being especially significant, in agreement with the historical record of impacts of drought. Fig. 3 shows the comparison of observed and simulated yields.

In all cases, meteorological variables explained a larger component of the year-to-year crop yield variability than did technology variables, even though sites have different significant climate variables. Drought appears as a key variable affecting crop yield over large areas of the country (Córdoba, Murcia and Valladolid), but is not significant in the sites that represent the wetter areas (Burgos and Logroño). In general, yields are negatively affected by high temperatureespecially in Murcia and Córdoba, which are the warmest sites. Low precipitation negatively affects yield at all sites, except in Burgos (the reference station for risk calculation, see below), especially in spring and fall owing to an increase in the crop water stress. In Córdoba, precipitation variables are not significant in the model, but the drought variable captures the effect of water deficit on crop yield. In most cases, winter and spring temperatures below 0 negatively affect crop yield. However, meteorological variables do not completely explain the evolution of yields and observed technological improvement: mechanization and fertilizers have clearly influenced the observed increase in productivity in almost every case.

\subsubsection{Sensitivity to drought}

Sensitivity analysis is essential when testing models, because models include parameters that represent random components of the system. It is also necessary to test the models that are unnecessarily complex.

We examined the sensitivity to drought via a likelihood-ratio test. We tested whether the group of 
Table 3. Estimated wheat model coefficients (Estim), p-values, and adjusted $\mathrm{R}^{2}$ values for different sites in Spain. Variables defined in Table 2. DJF: December, January, February; MAM: March, April, May; SON: September, October, November

\begin{tabular}{|c|c|c|c|c|c|c|c|c|c|c|}
\hline \multirow[t]{2}{*}{ Variable } & \multicolumn{2}{|c|}{ Burgos } & \multicolumn{2}{|c|}{ Valladolid } & \multicolumn{2}{|c|}{ Logroño } & \multicolumn{2}{|c|}{ Córdoba } & \multicolumn{2}{|c|}{ Murcia } \\
\hline & Estim & $\mathrm{p}$ & Estim & $\mathrm{p}$ & Estim & $\mathrm{p}$ & Estim & $\mathrm{p}$ & Estim & $\mathrm{p}$ \\
\hline $\ln Y_{t-1}$ & 0.2891 & 0.0118 & & & & & & & & \\
\hline Mac & 0.0033 & 0.0000 & 0.0020 & 0.0000 & 0.0040 & 0.0000 & & & 0.0017 & 0.0000 \\
\hline Fert & & & & & & & 0.0006 & 0.0001 & & \\
\hline $\operatorname{Tav}_{\mathrm{DJF}}$ & 0.0645 & 0.0049 & & & & & & & & \\
\hline $\operatorname{Tav}_{\mathrm{Apr}}$ & & & & & & & -0.1518 & 0.0047 & & \\
\hline $\mathrm{Fr}_{\text {May }}$ & -0.0404 & 0.0159 & & & & & & & & \\
\hline $\mathrm{Fr}_{\mathrm{SON}}$ & -0.0106 & 0.0059 & & & & & & & & \\
\hline $\mathrm{Fr}_{\mathrm{DJF}}$ & & & & & & & -0.0093 & 0.0492 & & \\
\hline Precip $_{M a r}$ & & & & & 0.0031 & 0.0216 & & & 0.0035 & 0.0013 \\
\hline Precip $_{\text {May }}$ & & & 0.0038 & 0.0033 & & & & & 0.0034 & 0.0025 \\
\hline Precip $_{\text {Dec }}$ & -0.0017 & 0.0085 & & & & & & & & \\
\hline $\operatorname{Tmax}_{\mathrm{Jan}}$ & & & & & & & -0.1514 & 0.0126 & & \\
\hline $\operatorname{Tmax}_{\text {May }}$ & -0.0262 & 0.0149 & & & & & & & & \\
\hline $\operatorname{Tmax}_{\mathrm{Jul}}$ & & & & & & & & & -0.0857 & 0.0030 \\
\hline $\operatorname{Tmax}_{\mathrm{Nov}}$ & & & -0.0532 & 0.0064 & & & & & & \\
\hline $\operatorname{Tmax}_{\mathrm{MAM}}$ & & & -0.0937 & 0.0002 & & & & & & \\
\hline $\operatorname{Tmax}_{\mathrm{SON}}$ & & & & & & & -0.0737 & 0.0909 & & \\
\hline $\mathrm{Dr}$ & & & -0.1726 & 0.0423 & & & -0.3320 & 0.0062 & -0.2138 & 0.0110 \\
\hline Imp1949 & & & & & -0.5296 & 0.0015 & & & & \\
\hline Imp1956 & & & -0.9205 & 0.0006 & 0.4613 & 0.0050 & & & & \\
\hline Imp1968 & & & & & & & 0.7143 & 0.0255 & & \\
\hline Imp1981 & & & & & & & & & -1.2966 & 0.0000 \\
\hline Imp1982 & & & & & -0.8633 & 0.0000 & & & & \\
\hline Imp1992 & & & -1.3424 & 0.0000 & & & & & & \\
\hline Imp1995 & & & & & & & & & -0.7908 & 0.0006 \\
\hline Ljung-Box Q1 & 0.1728 & 0.678 & 0.0267 & 0.8700 & 1.3807 & 0.2400 & 0.0951 & 0.7580 & 0.0276 & 0.868 \\
\hline Ljung-Box Q2 & 0.2385 & 0.888 & 0.8034 & 0.6690 & 2.3803 & 0.3040 & 3.4666 & 0.1770 & 0.1332 & 0.936 \\
\hline Ljung-Box Q3 & 0.3834 & 0.944 & 1.6921 & 0.6390 & 3.7169 & 0.2940 & 3.5136 & 0.3190 & 0.3866 & 0.943 \\
\hline Ljung-Box Q4 & 1.2150 & 0.876 & 1.9645 & 0.7420 & 4.2278 & 0.3760 & 3.6255 & 0.4590 & 1.7918 & 0.774 \\
\hline White test & 0.8724 & 0.5924 & 3.2038 & 0.0026 & 1.0850 & 0.3896 & 2.9930 & 0.0194 & 0.8287 & 0.6127 \\
\hline Log-likelihood & 27.5386 & & 3.4693 & & 26.9150 & & 2.8800 & & 15.1369 & \\
\hline $\mathrm{R}^{2}$ & 0.94 & & 0.75 & & 0.90 & & 0.68 & & 0.76 & \\
\hline
\end{tabular}

'drought variables' contributed to the overall explanation of the model. If the model was not sensitive to drought, then it is likely that the model was unnecessarily complex. We compared the non-restrictive

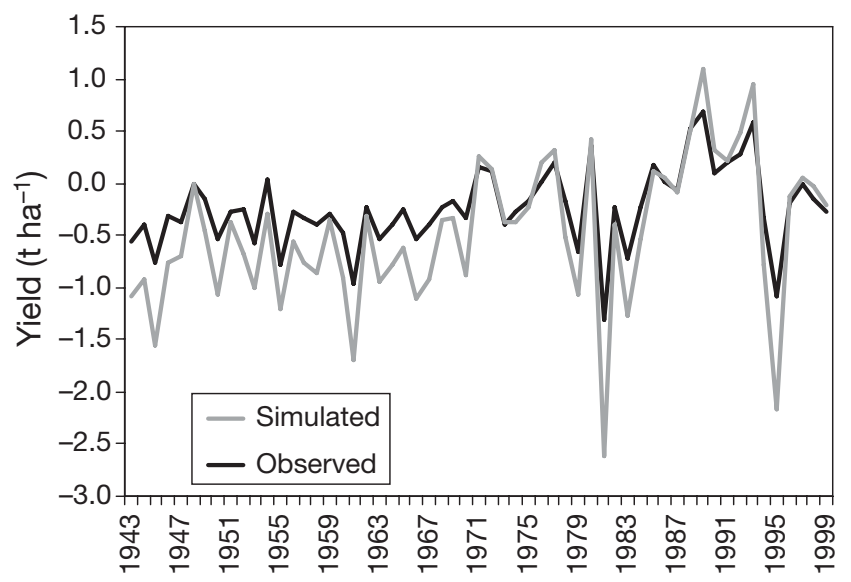

Fig. 3. Observed and fitted wheat yields in Murcia, Spain during 1940 to 2000 model $(L)$ with an alternative restricted model that excludes precipitation and drought as input variables $\left(L_{R}\right)$. According to the likelihood-ratio test, the likelihood value can be expressed as $2\left[\ln L-\ln L_{\mathrm{R}}\right]$; this expression is distributed as a $\chi^{2}$, where the degrees of freedom are the number of restrictions imposed on the model. Table 4 shows the likelihood-ratio test values and p-values obtained. In most cases, the set of drought variables are significant at $p<0.05$, and drought variables explain agricultural risk in all cases except in Logroño and Burgos. These results agree with the observations.

\subsection{Monte Carlo simulation}

We used Monte Carlo simulations to derive random samples (10000 values) of statistical distributions of crop yield, and therefore to analyse the distribution of probabilities in order to obtain a certain yield (the risk level). We evaluated the down-side risk (that is, the 
Table 4. Likelihood ratio to test drought effects on wheat yields among different sites in Spain. $L$ : non-restrictive model $_{i} L_{\mathrm{R}}$ : restrictive model

\begin{tabular}{|lccccc|}
\hline & Burgos & Valladolid & Logroño & Córdoba & Murcia \\
\hline $\ln L$ & 27.54 & 3.47 & 26.91 & 2.88 & 14.44 \\
$\ln L_{\mathrm{R}}$ & 23.42 & -4.68 & 23.21 & -2.33 & -3.90 \\
Likelihood & 8.24 & 16.30 & 7.41 & 10.42 & 36.68 \\
ratio-like test & & & & & \\
$\mathrm{df}$ & 1 & 2 & 1 & 1 & 3 \\
$\chi^{2}(\alpha=0.995)$ & 7.88 & 10.60 & 7.88 & 7.88 & 12.80 \\
$\chi^{2}(\alpha=0.95)$ & 3.84 & 5.99 & 3.84 & 3.84 & 7.81 \\
$\mathrm{p}$ & 0.005 & 0.000 & 0.007 & 0.002 & 0.000 \\
\hline
\end{tabular}

skewed data. Nevertheless, Córdoba and especially Logroño have a higher probability of obtaining results over the mean, as indicated by the skewness coefficients above +1 . Kurtosis is a parameter that describes the shape of a random variable's probability density function. The kurtosis coefficients of the data presented in Table 5 are greater than 3, indicating leptokurtic distributions: that is, that the probability distribution functions of the yields are simultaneously 'peaked' and have 'fat tails'.

The next step is to make comparisons among the geographic areas. We selected Burgos as the reference station for comparison because it presents a yield distribution function near 'normal' (Fig. 5). The analysis shows that risk characterization is complex, owing to the multiple attributes of risk beyond variability; therefore, we further analyse a risk measure in the following section.

\subsection{Risk factor}

RF curves were estimated for yields at each site (Fig. 6). Burgos was selected as the reference station because the yield distribution here is nearly 'normal' (Fig. 5), the yield variability is explained only by technology and climate variables, and the model does not include impulse interventions (see Table 3). To include the comparative analysis with the risk curves, it was necessary to standardise the data. As in Ferreyra et al. (2001), we compared RF curves and focused
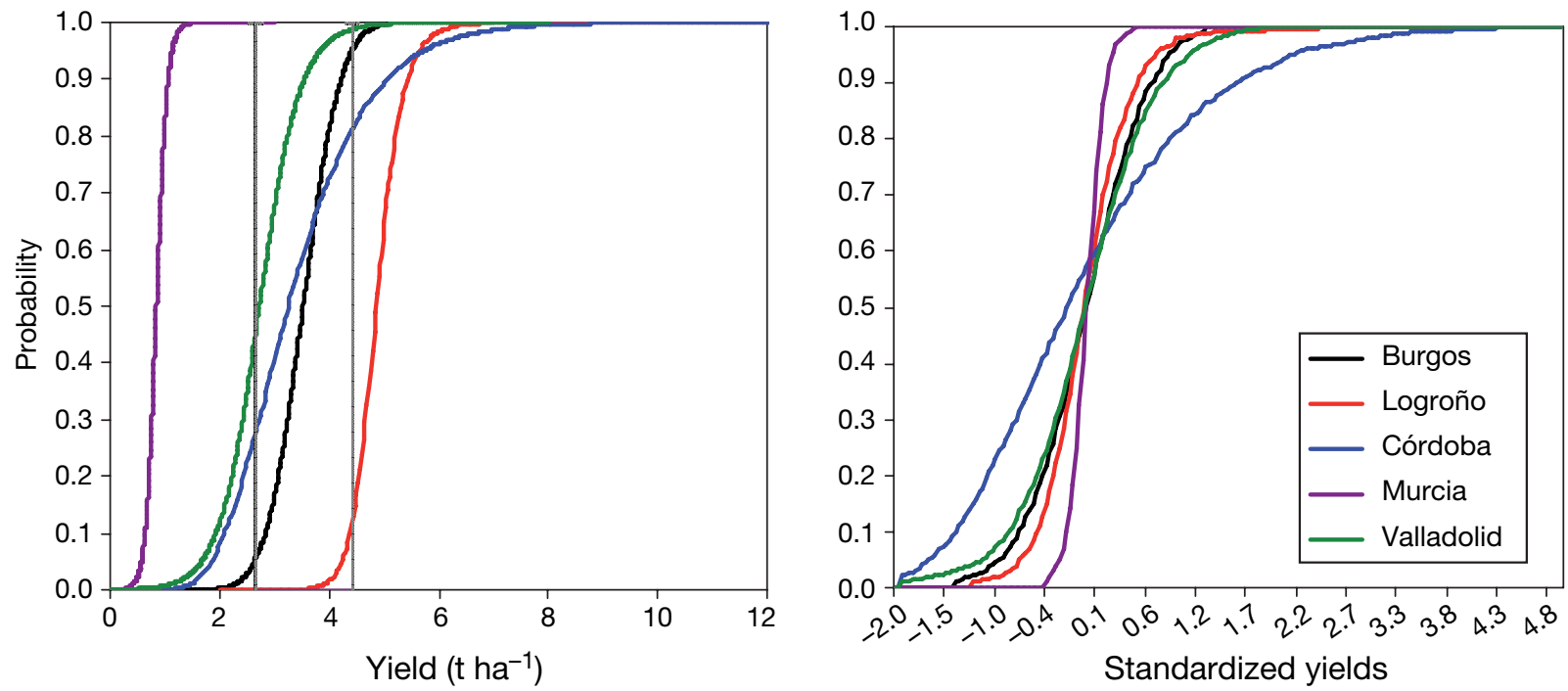

Fig. 4. Accumulated density probability functions of wheat crop yield in different locations in Spain. Left: non-standardized right: standardized 


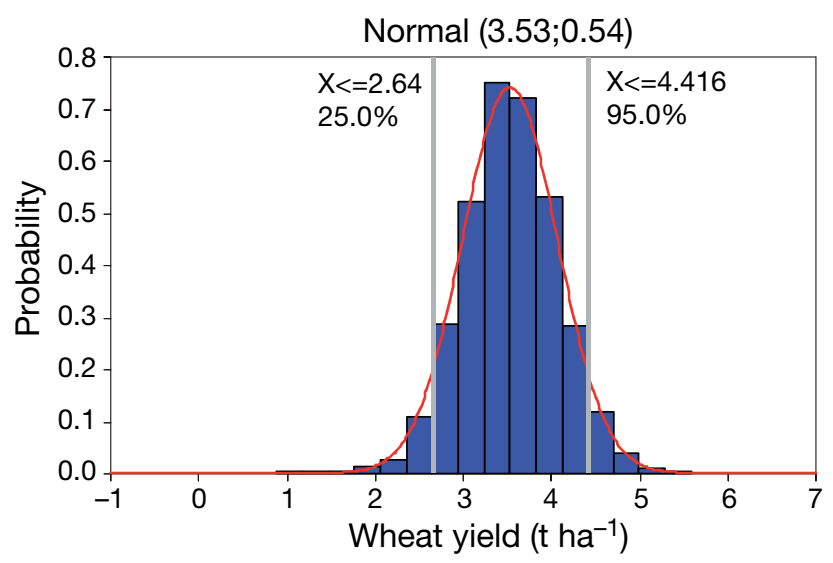

Fig. 5. Distribution function of simulated yields in Burgos; distribution is normal, with mean $=3.53$ and $\mathrm{SD}=0.54$

Table 5. Statistical properties of wheat simulations

\begin{tabular}{|lccccc|}
\hline & Burgos & \multicolumn{2}{c}{ Valladolid Logroño } & Córdoba & Murcia \\
\hline Mean & 3.53 & 2.74 & 4.98 & 3.46 & 0.85 \\
Median & 3.53 & 2.72 & 4.85 & 3.27 & 0.84 \\
Mode & 3.56 & 2.65 & 4.86 & 2.72 & 0.81 \\
SD & 0.54 & 0.68 & 0.87 & 1.25 & 0.19 \\
CV & 0.15 & 0.25 & 0.17 & 0.36 & 0.22 \\
Maximum & 6.47 & 7.01 & 16.36 & 16.89 & 2.99 \\
Minimum & 0.01 & 0.27 & 2.62 & 0.81 & 0.10 \\
Skewness & -0.15 & 0.14 & 4.12 & 1.55 & 0.30 \\
Kurtosis & 4.08 & 5.03 & 26.66 & 8.97 & 8.39 \\
\hline
\end{tabular}

our discussion on 4 'reference quantiles', the 10th, 33rd, 66th, and 90th percentiles (denoted $q_{10}, q_{33}, q_{66}$ and $\left.q_{90}\right)$, for the reference set. These quantiles define outcomes (1) 'much below normal' (outcomes $<q_{10}$ ), (2) 'below normal' (outcomes $<q_{33}$ ), (3) 'above normal' (outcomes $>q_{66}$ ), and (iv) 'much above normal' (outcomes $>q_{90}$ ).

The risk curves show that the probability of not exceeding $q_{10}$ in Córdoba and Valladolid is higher than the reference set probability, meaning that these are the regions with more risk in the context of 'much below normal' yields. In contrast, Logroño (La Rioja) has the lowest risk factor and Murcia has almost the same risk level as Burgos in this quantile. The results are similar when the yields are 'below normal', except in Murcia, which has the lowest risk factor in this situation. Therefore, the probability of exceeding 'below normal' yields is greater in Murcia than in the other areas.

In the case of 'above normal' and 'much above normal' yields, Córdoba has the lowest risk factor, so the probability of exceeding a determined level of yield is larger in Córdoba than in other areas. Murcia is the area with the most risk of not exceeding these high lev-

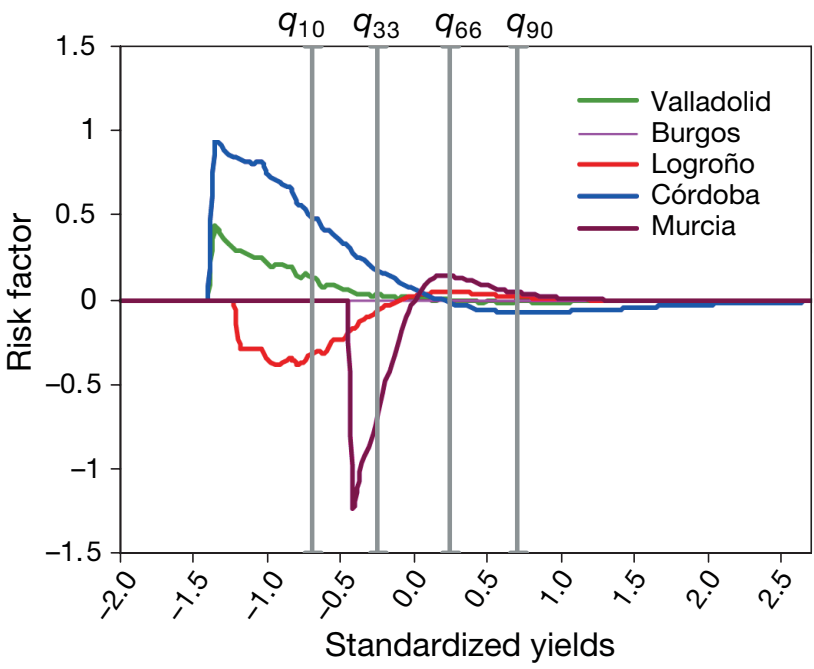

Fig. 6. Yield factor curve for wheat at selected sites in Spain. The 4 values on the $x$-axis indicate (from $L$ to R) the yield for percentiles $q_{10}, q_{33}, q_{66}$ and $q_{90}$. The scale on the $y$-axis indicates the ratio of cumulative probabilities. Negative values of the risk factor (RF) indicate lower risk in the percentile considered; positive values of RF indicate a higher risk in the percentile considered

els of yield. The remainder of the sites have a similar probability of exceeding 'much above normal' outcomes. In fact, the risk level depends on the level of the yields. Locations with higher yield do not have lower risk. For example, Córdoba has a higher average yield than does Murcia, and at the same time has a greater risk of not exceeding above or much above normal yields than Murcia.

\section{CONCLUSIONS}

Over the next few decades, a central goal in agricultural decision-making will be to decrease the risk associated with a changing climate. Fundamental to this aim is the development of our ability to quantify climate risks associated with different geographical locations. Previous studies have used crop models to represent agricultural responses to climate (Saarikko \& Carter 1996, Wolf et al. 1996, Hansen \& Jones 2000, Parry et al. 2004, Lobell \& Ortiz-Monasterio 2006), mainly owing to the lack of observed data. While these approaches have proven effective when analyzing potential scenarios, their lack of historical perspective limits their application by stakeholders. Our results show that observed yield patterns contain substantial information on the relative importance of climate and management variables for yield variability. The method developed in this study links observations with the analysis of probabilistic properties of climatedriven agricultural yields. Spatial and temporal vari- 
ability in climate was considered, thus responding to the critical need for knowledge on crop responses to rainfall and extreme temperature events. Our methods were applied over a transect of climatic conditions in Spain, and the information obtained is potentially valuable to our understanding of past and future climate constraints.

In general, the yield of wheat in Spain has exhibited an increasing trend and increased variability over the period 1940 to 2000, especially since the 1970s. We evaluated the influence of climatic and non-climatic variables on final crop yield. Our results show that rainfed yields are negatively affected by high temperature-over a threshold that increases evapotranspiration and therefore hydrological stress - and by low precipitation, especially in the spring. Winter and spring temperatures below freezing are also factors that negatively impact crop yield. Drought affects a great portion of the crop production in Spain, implying that competition for the use of water plays a crucial role in agricultural decisions.

Here we derived random samples of data to evaluate the probability of achieving low yields as a consequence of critical climate variables: such statistical distributions of crop yields are used for developing agricultural insurance products to climate (Iglesias et al. 2006). Finally, the method of deriving a risk factor was compared among 5 sites. Our results agree with the agronomic knowledge of crop responses to climate, but the risk ranking of the regions is not intuitive when only considering isolated variables. For example, Murcia is a very drought-sensitive region, and the common perception is that the risk of crop production is higher. Our results show that the integration of a range of climatic variables is crucial for quantifying agricultural risk and establishing a risk level for management alternatives. Farmers and agricultural planners may use the derived models to estimate the probably of achieving a target yield level in different climate scenarios. New advances in monitoring and forecasting seasonal weather, especially drought, may include the derived models in order to develop early warning systems. Forecasts of expected future yields are very important for planning inputs or production, or for scheduling loans to farmers. The information derived from the risk analysis can be directly used by insurance companies in order to evaluate the risk premium from the estimated yield functions and the probability of drought.

The methods used here only address the supply side of agricultural risk; markets and policies were not considered, and these will certainly determine the results of agricultural activities, especially in Europe (Rounsewell et al. 2005). Major limitations of our results arise from the simplicity of the variables considered in the empirical models, the aggregation of some data vari- ables, and the quality of data. The limitations in the application of the approach are a consequence of the availability of data in many regions. Nevertheless, climate-driven crop models could provide proxy crop yield data, and it may be important to compare the results of climate risks derived from them.

Finally, the approach presented here can be readily extended to analyse additional crop production factors that interact with climate, such as water demand, fertiliser applications, and diffuse pollution. While simple functions of crop-climate interaction will never provide the detail possible with more complex models, the direct interpretation of the results by farmers and policy-makers may be of great value to the risk management decision-making process.

Acknowledgements. We acknowledge funding provided by the EU MEDA Water Project MEDROPLAN (Mediterranean Drought Planning) and support of the Spanish Science and Technology Project CICYT SEJ205-05085 (dynamic models for optimisation of agro-forestry systems).

\section{LITERATURE CITED}

Adams RM, Houston L, McCarl B, Tiscareño M, Matus J, Weiher R (2003) The benefits to Mexican agriculture of an El Niño-Southern Oscillation (ENSO) early warning system. Agric For Meteor 115:183-194

Akaike H (1973) A maximum likelihood estimation of Gaussian autoregressive moving average models. Biometrika 60:255-265

Atwood J, Shaik S, Watts M (2003) Are crop yields normally distributed? A re-examination. Am J Agric Econ 85: 888-901

Bonaccorso B, Cancelliere A, Rossi G (2003) An analytical formulation of return period of drought severity. Stoch Environ Res Risk Assess 17:157-174

Botterill LC, Wilhite DA (2005) From disaster response to risk management. Springer, Dordrecht

Bradford RB (2000) Drought events in Europe. In: Vogt JV, Somma F (eds) Drought and drought mitigation in Europe. Kluwer Academic, Dordrecht, p 7-20

Cane MA, Eshel G, Buckland RW (1994) Forecasting Zimbabwean maize yield using eastern equatorial Pacific sea surface temperature. Nature 371:204-205

Ferreyra RA, Podestá GP, Messina CD, Lestón D, Dardanelli J, Guevara E, Meira S (2001) A linked-modeling framework to estimate maize production risk associated with ENSO-related climate variability in Argentina. Agric For Meteorol 107:177-192

Garrote L, Flores F, Iglesias A (2007) Linking drought indicators to policy. The case of the Tagus Basin drought plan. Water Res Manage (in press)

Gibbons J, Ramsden SJ (2005) Robustness of recommended farm plans in England under climate change: a Monte Carlo simulation. Clim Change 68:113-133

Hammer GL, Holzworth DP, Stone R (1996) The value of skill in seasonal climate forecasting to wheat crop management in a region with high climate variability. Aust J Agric Res 47:717-773

Hansen JW, Indeje M (2004) Linking dynamic seasonal climate forecasts with crop simulation for maize yield prediction in semi-arid Kenya. Agric For Meteorol 125:143-157 
Hansen JW, Jones JW (2000) Scaling-up crop models for climate variability applications. Agric Syst 65:43-72

Hansen JW, Potgieter A, Tippett MK (2004) Using a general circulation model to forecast regional wheat yields in northeast Australia. Agric For Meteorol 127:77-92

Hertzler G (2005) Prospects for insuring against drought in Australia. In: Botterill LC, Wilhite DA (eds) From disaster response to risk management: Australia's national drought policy. Springer, Dordrecht

Iglesias A, Moneo M (2005) Drought preparedness and mitigation in the Mediterranean: analysis of the organizations and institutions. Options Méditerranéennes, Paris

Iglesias A, Rosenzweig C, Pereira D (2000) Agricultural impacts of climate in Spain: developing tools for a spatial analysis. Glob Environ Change 10:69-80

Iglesias A, Moneo M, Cancelliere A (2006) Drought management guidelines. Options Méditerranéennes, Paris

Iglesias A, Garotte L, Flores F, Moneo M (2007a) Drought preparedness and monitoring: dealing with risk and climate change in the Mediterranean. Water Res Manage (in press)

Iglesias A, Moneo M, Garrote L, Flores F (2007b) Drought and water scarcity: current and future vulnerability and risk. In: Garrido A, Llamas MR (eds) Issues in water resource policy: resources for the future. Resources for the Future, Washington, DC (in press)

Jones JW, Hansen JW, Royce FS, Messina CD (2000) Potential benefits of climate forecasting to agriculture. Agric Ecosyst Environ 82:169-184

Just RE, Weninger Q (1999) Are crop yields normally distributed? Am J Agric Econ 81:287-304

Kang H (1985) The effects of detrending in Granger Causality Tests. J Bus Econ Stat 3:344-349

Keyantash J, Dracup JA (2002) The quantification of drought. An evaluation of drought indices. Bull Am Meteorol Soc 83:1167-1180

Kumar KK, Kumar RK, Ashrit RG, Deshpande NR, Hansen JW (2004) Climate impacts on Indian agriculture. Int J Climatol 24:1375-1393

Limaye AS, Paudel KP, Musleh F, Cruise JF, Hatch LU (2004) Economic impacts of water allocation on agriculture in the lower Chattahoochee River basin. Hydrol Sci Technol J 20:75-92

Lobell DB, Ortiz-Monasterio JI (2006) Regional importance of crop yield constraints: linking simulation models and geostatistics to interpret spatial patterns. Ecol Model 196: 173-182

Lobell DB, Ortiz-Monasterio JI, Asner GP, Naylor R, Falcon W, Matson P (2005) Analysis of wheat yield and climatic trends in Mexico. Field Crops Res 94:250-256

Luo H, Skees JR, Marchant MA (1994) Weather information and the potential for the inter-temporal adverse selection in crop insurance. Rev Agric Econ 16:441-451

MAPA (2004) Anuarios de estadística agroalimentaria: 19402000. Ministry of Agriculture, Madrid

McKay MD, Conover WJ, Beckman RJ (1979) A comparison of three methods for selecting values of input variables in the analysis of output from a computer code. Technometrics 221:239-245

Editorial responsibility: Gregory Jones, Ashland, Oregon, USA
McKee TB, Doesken NJ, Kliest J (1993) The relationship of drought frequency and duration to time scales. Proc 8th Conf Appl Climatol, 17-22 January, Anaheim, CA. Am Meteorol Soc, Boston, p 179-184

Messina CD, Hansen JW, Hall AJ (1999) Land allocation conditioned on ENSO phases in the pampas of Argentina. Agric Syst 60:197-212

Mjelde JW, Thompson TN, Hons FM, Cothren JT, Coffman CG (1997) Using southern oscillation information for determining corn and sorghum profit-maximizing input levels in east-central Texas. J Prod Agric 19:168-175

Mjelde JM, Hill H, Griffiths JF (1998) A review of current evidence of climate forecasts and their economic effects in agriculture. Am J Agric Econ 5:1089-195

Moneo M (2005) Agricultural vulnerability to drought: a comparative study in Morocco and Spain. CIHEAM International Agronomic Institute, Zaragoza

Ogallo LA, Boulahya MS, Keane T (2000) Applications of seasonal to interannual climate prediction in agricultural planning and operations. Agric For Meteorol 103:159-166

Parry MA, Rosenzweig C, Iglesias A, Livermore M, Fisher G (2004) Effects of climate change on global food production under SRES emissions and socio-economic scenarios. Glob Environ Change 14:53-67

Patt AG (1999) Extreme outcomes: the strategic treatment of low probability events in scientific assessments. Risk Decision Policy 4:1-15

Robert CP, Casella G (1999) Monte-Carlo statistical methods. Springer, New York

Robert CP, Casella G (2004) Monte Carlo statistical methods, 2nd edn. Springer, New York

Rossi G, Cancelliere A, Pereira LS, Oweis T, Shataniawi M, Zairi A (eds) (2003) Tools for drought mitigation in Mediterranean regions. Kluwer Academic, Dordrecht

Rounsewell MDA, Ewert F, Reginster I, Leemans R, Carter TR (2005) Future scenarios of European agricultural land use. II. Projecting changes in cropland and grassland. Agric Ecosyst Environ 107:117-135

Saarikko RA, Carter TR (1996) Estimating the development and regional thermal suitability of spring wheat in Finland under climatic warming. Clim Res 7:243-252

Schwarz G (1978) Estimating the dimension of a model. Ann Stat 6:461-464

UNISDR (2002) Drought living with risk: an integrated approach to reducing societal vulnerability to drought. UN International Strategy for Disaster Reduction, Ad Hoc Discussion Group on Drought, Geneva

Wilhite DA (2005) Drought and water crisis. Science, technology and management issues. Taylor \& Francis, New York

White H (1980) A heteroscedasticity-consistent covariance matrix estimator and a direct test for heteroscedasticity. Econometrica 48:817-838

Wisner B, Blaikie P, Cannon T, Davis I (2004) At risk: natural hazards, people's vulnerability and disasters. Routledge, Wiltshire

Wolf J, Evans LG, Semenov MA, Eckersten H, Iglesias A (1996) Comparison of wheat simulation models under climate change. I. Model calibration and sensitivity analysis. Clim Res 7:271-281

Submitted: June 14, 2006; Accepted: March 12, 2007

Proofs received from author(s): April 23, 2007 